OPEN ACCESS

Edited by:

Jun Niu,

China Agricultural University, China

Reviewed by:

Huaiwei Sun,

Huazhong University of Science and

Technology, China

Dengfeng Liu,

Xi'an University of Technology, China

*Correspondence:

Biqiong Dong

bqdong92@126.com

Xizhi LV

nihulvxizhi@163.com

Specialty section:

This article was submitted to

Hydrosphere,

a section of the journal

Frontiers in Earth Science

Received: 16 December 2021

Accepted: 24 January 2022

Published: 02 March 2022

Citation:

Qin T, He S, Liu S, Nie H, Dong B and Lv X (2022) Optimal Allocation of Slope Ecological Restoration for the Climate

Change Mitigation and Natural

Function Improvement.

Front. Earth Sci. 10:837311.

doi: 10.3389/feart.2022.837311

\section{Optimal Allocation of Slope Ecological Restoration for the Climate Change Mitigation and Natural Function Improvement}

\author{
Tianling Qin ${ }^{1}$, Shan $\mathrm{He}^{2}$, Shanshan Liu ${ }^{1}$, Hanjiang $\mathrm{Nie}^{3}$, Biqiong Dong ${ }^{1 *}$ and Xizhi $\mathrm{Lv}^{4 *}$ \\ ${ }^{1}$ State Key Laboratory of Simulation and Regulation of Water Cycle in River Basin, China Institute of Water Resources and \\ Hydropower Research, Beijing, China, ${ }^{2}$ Bureau of South to North Water Transfer of Planning, Designing and Management, \\ Ministry of Water Resources, Beijing, China, ${ }^{3}$ Key Laboratory for Geographical Process Analysis \& Simulation of Hubei Province, \\ College of Urban and Environmental Sciences, Central China Normal University, Wuhan, China, ${ }^{4}$ Yellow River Institute of Hydraulic \\ Research, Henan Key Laboratory of Yellow Basin Ecological Protection and Restoration, Zhengzhou, China
}

The key to dealing with extreme problems at watershed or region scales in the context of climate change is the "de-extremalization" of hydrological processes. The foundation lies in how to optimize the allocation of ecological restoration on slopes to mitigate the extreme impacts of climate change on hydrological processes and improve ecological service functions. Previous studies focused on analyzing the direct effects of slope land use, vegetation distribution, or historical pattern of ecological restoration on runoff processes. This study developed a slope ecological restoration evaluation system to evaluate the naturalness, functional types, and functional coordination of slope ecological restoration at different historical stages and quantitatively identified the mitigation effect on climate change in the future, which was applied to the Huangshui River Basin (above Minhe County) in Qinghai Province, China. Based on the land suitability evaluation methods, a set of layout schemes were constructed. The runoff mutation and ecological function of different schemes under climate change were evaluated, and the highly suitable scheme was selected as the optimal scheme. Compared with the current situation, the coupling coordination degree index of the scheme would increase from 0.32 to 0.59 . Meanwhile, the runoff and coefficient of variation would decrease by $30 \%$ and $60 \%$, respectively, during the wet season under the high-emission scenario RCP8.5. This study closely links the ecological construction of slopes with the response to extreme climates, which provides technical methods and practical support for the optimization of regional ecological patterns and scientific water governance modes.

Keywords: slope ecological restoration, evaluation system, optimal allocation, climate change, mitigation

\section{INTRODUCTION}

In the context of climate change, the frequency and intensity of extreme drought and flood events in most mid-latitude terrestrial and tropical humid regions around the world have shown an increasing trend (IPCC, 2014). The key to dealing with large-scale extreme problems in watersheds or regions lies in the "de-extremalization" of hydrological processes (Yan et al., 2017; Zhang et al., 2020), as well as repairing the terminal governance and process separation problems in traditional water 
governance modes (Yan et al., 2020), and improving the mitigation capacity of slope measures to extreme hydrological processes. Slope ecological restoration is an important measure for the construction of Nature-Enriched-AttributesCoordinated-Watershed (Yan et al., 2017; Yan et al., 2020). On the one hand, it directly affects vertical hydrological processes such as the atmospheric water vapor flux (Fathizadeh et al., 2017; Ghimire et al., 2017; Liu J. et al., 2018b), soil water movement (Wu et al., 2017; Huang et al., 2017; Yu et al., 2018; Bo et al., 2021; Xu M. et al., 2021), and evapotranspiration (Li et al., 2016; Wang et al., 2018). On the other hand, the canopy structure and community succession of vegetation indirectly affect the horizontal hydrological processes such as runoff generation and confluence on the slope (Amenu and Kumar, 2008; Yang et al., 2010; Dong et al., 2021) by changing the underlying surface conditions and the surface roughness. Aiming at mitigating the extreme impacts of climate change on hydrological processes and improving ecological service functions, how to optimally allocate ecological restoration on slopes has become one of the key scientific issues in the intersecting fields of climatology, ecology, and hydrology.

At present, the evaluation index of ecological restoration focused on the regulation of ecological function and hydrological process (Nunes et al., 2016; Li et al., 2018; He Z. et al., 2019), such as peak reduction of the runoff, landscape pattern, and ecological service value. Most researchers evaluated ecological restoration, respectively, from the above two aspects. A comprehensive index system, which includes scale, composition, pattern, and eco-hydrological function at the basin scale is needed. Allocation of ecological restoration was based on ecology theory, which was mainly conducted at the rural and urban scales (Li Y. et al., 2017; Zhang and Chen, 2017; Liu J. et al., 2018b), with the common optimization goals of urban pattern, storm water resource management, and ecological service function improvement ( $\mathrm{Li}$ and Li, 2019b; Liu J. et al., 2018b; Liu, 2019; Jiang et al., 2021), using traditional landscape ecology methods, geographic information technology, and morphological pattern analysis methods (Li and Li, 2019b; Liu, 2019). However, few studies focused on the impacts of the optimal layout of largescale slope ecological restoration on extreme hydrological processes. Regarding the research of the mitigation effect of slope ecological restoration construction on climate change, scholars mainly adopt three kinds of methods. The first one is the theoretical derivation method based on the law of conservation of mass. This method mainly reveals the climate impact from the macro-mechanism level, while it is difficult for this method to accurately quantify the historical distribution of slope vegetation or the extent and magnitude of the influence of ecological restoration (Zhou and Wang, 1999). The second method is the statistical relationship analysis method based on prototype observation, reanalysis data, and remote sensing interpretation (Li X. et al., 2017; Wang et al., 2019; Jin et al., 2020). This method is relatively convenient, but the limitation of data sequence length and spatial accuracy leads to uncertainty in the analysis of mitigation effects. The third one is land surface-hydrological numerical simulation method based on climate models (López-Bravo et al., 2018; Zheng et al., 2020), which uses land use change or forest and grass cover scenarios to simulate and analyze runoff changes under climate change (Yang et al., 2019; Li et al., 2009; Bai et al., 2020; Wang et al., 2020) or feedback of the land cover on local climate (Hua et al., 2015; Li et al., 2017; Zheng et al., 2020). The above methods focused on analyzing the direct effects of slope land use, vegetation distribution, or historical pattern of ecological restoration on runoff processes under the impact of climate change. Few studies investigated the mitigation effect of optimizing the layout of slope ecological restoration on climate change.

To solve the aforementioned key scientific issues, this study took the Huangshui River Basin (above Minhe County) in Qinghai Province, China, as the study area. An evaluation index system for slope ecological restoration was constructed, which includes the naturalness, functional types, and functional coordination of slope ecological restoration in different historical stages. A set of layout schemes was acquired based on the land suitability evaluation method. The runoff mutation and ecological function of different layout schemes in the context of climate change were evaluated based on the distributed hydrological model (WEP) (He S. et al., 2019) and geographic information technology, and the optimal layout schemes were selected. This study closely links the ecological construction of slopes with the mitigation to extreme climates, which provides technical methods and practical support for the optimization of regional ecological patterns and scientific water governance modes.

\section{MATERIALS AND METHODS}

\subsection{Study area}

Huangshui River is a first-degree tributary of the upper reaches of the Yellow River, which rises in the Haibei Tibetan Autonomous Prefecture of Qinghai Province. Huangshui River Basin lies in the transition zone between the Qinghai-Tibet Plateau and the Loess Plateau with a typical feature of ecological fragility. The study site covers most of the Huangshui River basin from the upper reaches of the Yellow River to Minhe County. The main stream length of the region is $278 \mathrm{~km}$ with a drainage area of $15,558 \mathrm{~km}^{2}$ (Figure 1). The terrain of the region is lower in the southeast and higher in the northwestern, which has an elevation change of 3,107 $\mathrm{m}$ from the river source to the mouth (Liu F. et al., 2020). The region experiences an arid and semi-arid continental climate with the mean average precipitation of $381.1 \mathrm{~mm}$ (1960-2017 records), and the mean average air temperature from $3.1^{\circ} \mathrm{C}$ to $7.9^{\circ} \mathrm{C}(1960-2017$ records) (He S. et al., 2019). The mean annual runoff at the Minhe hydrological station (the outlet of the basin) was approximately 2,053 million $\mathrm{m}^{3}$ (1956-2000 records). According to the land use classification results of 2017, forest was the main type of land use, followed by grasslands and cropland, occupying $92.91 \%$ in total. The main vegetation types were forests, temperate shrubs, grasslands, and meadows (Feng et al., 2013). 


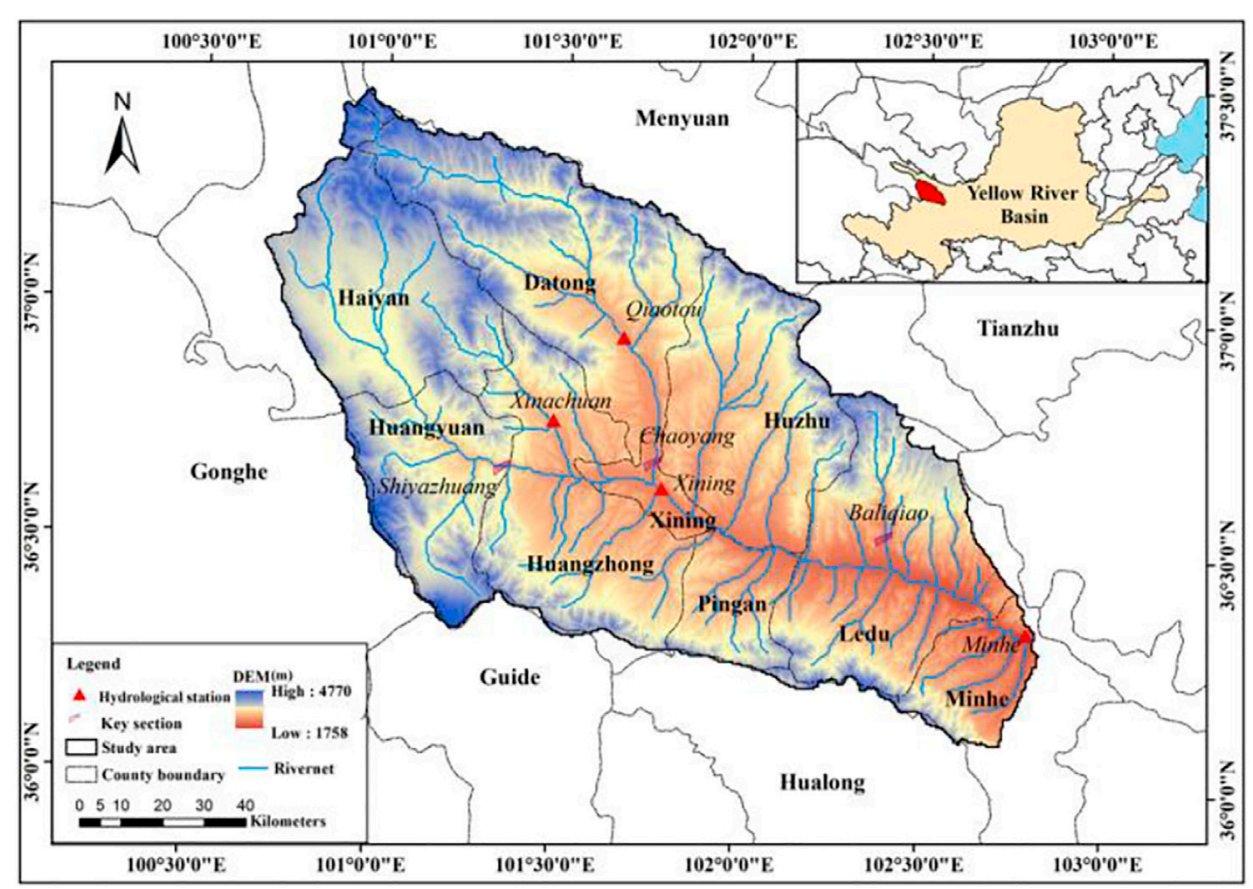

FIGURE 1 | Location of the Huangshui River Basin.

TABLE 1 | Data type, source, and description.

\begin{tabular}{|c|c|c|c|}
\hline Data type & Parameters & Source & Description \\
\hline Meteorology & $\begin{array}{l}\text { Surface temperature } \\
\text { Relative humidity } \\
\text { Wind speed } \\
\text { Precipitation } \\
\text { Sunshine duration }\end{array}$ & China Meteorological Data Service Centre & $\begin{array}{l}\text { Daily observations of six } \\
\text { Meteorological Stations (1960-2017) }\end{array}$ \\
\hline $\begin{array}{l}\text { Administrative } \\
\text { divisions }\end{array}$ & Municipal and county administrative divisions & National Geomatic Centre of China & / \\
\hline Land use & Land use type & $\begin{array}{l}\text { National Geomatic Centre of China and } \\
\text { Department of Nature Sources of Qinghai } \\
\text { Province, China }\end{array}$ & Land Use in 1980, 2005, and 2017 \\
\hline $\begin{array}{l}\text { Future climate } \\
\text { scenario }\end{array}$ & $\begin{array}{l}\text { Precipitation, average temperature, average relative } \\
\text { humidity, near-surface average wind speed, and total } \\
\text { solar radiation }\end{array}$ & $\begin{array}{l}\text { Intergovernmental Panel on Climate Change } \\
\text { (IPCC); } \\
\text { Inter-Sectoral Impact Model } \\
\text { Inter-Comparison Project (ISI-MIP) }\end{array}$ & Daily data from 2021 to 2050 \\
\hline
\end{tabular}

\subsection{MATERIALS}

The basic data required for this study include topography data, meteorology data, soil data, administrative division data, land use data, hydrological data, and future climate scenario data (Table 1). This study uses three main future climate change scenarios in the IPCC-AR5 report: high-emission scenario RCP8.5, medium-emission scenario RCP4.5, and low-emission scenario RCP2.6 (IPCC, 2012; Xu and Xu, 2012). Five general circulation models provided by ISI-MIP (The Inter-Sectoral Impact Model Intercomparison Project) were selected, including GFDL-ESM2M, HADGEM2-ES, IPSL-CM5A-LR, 


\section{Optimal Allocation of Slope Ecological Restoration for the Climate Change}

Mitigation and Natural Function Improvement

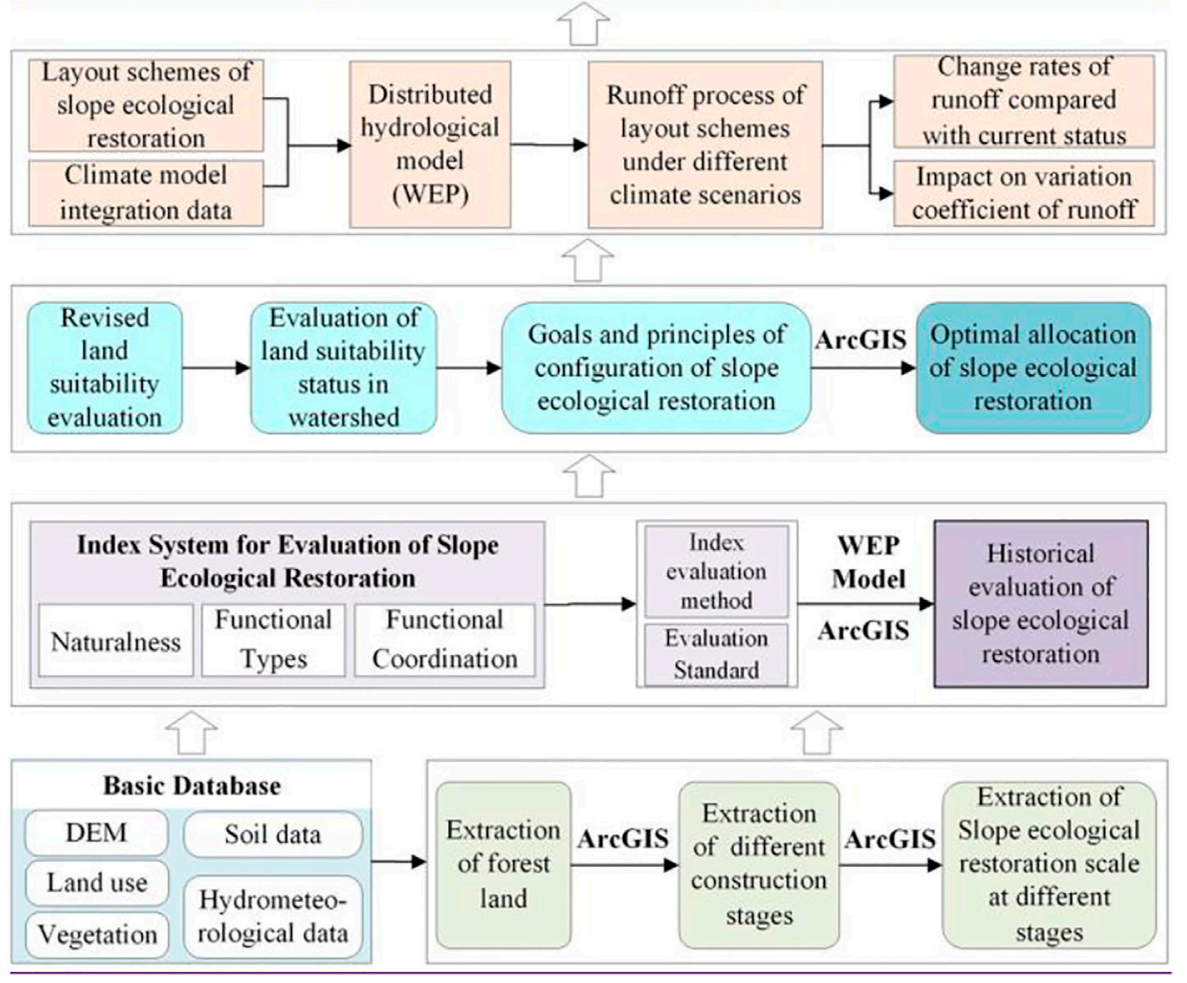

FIGURE 2 | Workflow for the optimal allocation of slope ecological restoration for the climate change mitigation and natural function improvement.

MIROC-ESM-CHEM, and NORESM1-M (Piani et al., 2010; Warszawski et al., 2014). The involving meteorological parameters are precipitation, average temperature, average relative humidity, near surface average wind speed, and total solar radiation. The time range is from January 1, 2021 to December 31, 2050.

\subsection{Methods}

An evaluation index system for slope ecological restoration was constructed to evaluate the naturalness, functional type, and functional coordination. Evaluation criteria and comprehensive evaluation methods were proposed for the evaluation of slope ecological restoration in different historical stages in the Huangshui River Basin. A set of slope ecological restoration layout schemes was developed as the underlying surface scenarios based on the improved land suitability evaluation method. Different climate model data and underlying surface scenarios were adopted to drive the distributed hydrological model (WEP) to obtain runoff processes under different composite backgrounds. The impacts of climate change on the volume and variability of runoff under different slope ecological restoration layout schemes were quantitatively analyzed. The overall mitigation effects of slope ecological restoration on climate change were identified. Additionally, considering the evaluation results of the slope ecological restoration under different layout schemes, the optimal layout schemes were selected (Figure 2).

\subsubsection{Historical evaluation of slope ecological restoration}

(1) Evaluation index system

Based on the ArcGIS platform, the slope ecological restoration scale at different construction stages (1980-2000, 2000-2017, 1980-2017) were acquired and used for subsequent evaluation (He S. et al, 2019). Focusing on the concept of Nature-Enriched-AttributesCoordinated-Watershed (Yan et al., 2020), based on the principles of respecting and conforming to nature, ecological restoration evaluation index system involving naturalness, functional types, and functional coordination was developed. The naturalness is commonly defined as the divergence of the ecosystem's biodiversity or current state from its natural steady state (Eichner and Tschirhart, 2007; Winter, 2012). In this study, we evaluated the naturalness from the scale, composition and the quality of the slope ecological restoration. Meanwhile, the evaluation index system aims to evaluate the hydrological adjustment function, ecological support function, climate regulation function, and ecological service function (serving the economy and society) of the whole watershed. The hydrological adjustment function mainly focused on the plant transpiration and runoff variation. The ecological support function referred to the water conservation, wind prevention, and sand fixation function. The climate 
TABLE 2 | Index system for evaluation of slope ecological restoration.

\begin{tabular}{|c|c|c|c|c|c|}
\hline First level & \multicolumn{2}{|c|}{ Second level indicator } & Interpretation & Equation & Parameter description \\
\hline \multirow[t]{3}{*}{ Naturalness } & $\begin{array}{l}\text { Slope ecological } \\
\text { restoration scale }\end{array}$ & Green area ratio & $\begin{array}{l}\text { Percentage of slope } \\
\text { ecological restoration } \\
\text { area }\end{array}$ & $G=S_{-} w / S$ & $\begin{array}{l}S_{-} w \text { is slope ecological } \\
\text { restoration area, } S \text { is the total } \\
\text { area of the basin }\end{array}$ \\
\hline & $\begin{array}{l}\text { Slope ecological } \\
\text { restoration } \\
\text { composition }\end{array}$ & $\begin{array}{l}\text { Biological } \\
\text { abundance index }\end{array}$ & $\begin{array}{l}\text { Abundance of species } \\
\text { per unit area }\end{array}$ & $S_{-} i=A_{-}$bio $\times \sum_{i=1}^{5}\left(a_{i} * x_{i}\right)$ & $\begin{array}{l}\text { A_bio is the normalization } \\
\text { coefficient with a references } \\
\text { value of } 511.26 \text { Ministry of } \\
\text { Ecology and Environment, } \\
\text { People's Republic of China, } \\
(2015), a_{i} \text { is the typical parameter } \\
\text { for different land uses, } x_{i} \text { is the } \\
\text { proportion of the area of different } \\
\text { land uses }\end{array}$ \\
\hline & $\begin{array}{l}\text { Quality of slope } \\
\text { ecological } \\
\text { restoration }\end{array}$ & Ecological integrity & $\begin{array}{l}15 \text { landscape pattern } \\
\text { indexes }\end{array}$ & $\begin{array}{l}\text { The indexes are percentage of landscape, } \\
\text { number of patches, largest patch index, edge } \\
\text { density, average patch area, area-weighted } \\
\text { mean patch fractal dimension index, } \\
\text { contagion index, aggregation index, Shannon } \\
\text { diversity index, Shannon evenness index on } \\
\text { patch metrics and landscape metrics }\end{array}$ & $\begin{array}{l}\text { The lower the degree of } \\
\text { landscape fragmentation, the } \\
\text { higher the ecological integrity }\end{array}$ \\
\hline \multirow[t]{6}{*}{$\begin{array}{l}\text { Functional } \\
\text { types }\end{array}$} & \multirow[t]{2}{*}{$\begin{array}{l}\text { Hydrologic } \\
\text { regulation } \\
\text { function }\end{array}$} & $\begin{array}{l}\text { Annual plant } \\
\text { transpiration per unit } \\
\text { area }\end{array}$ & / & $E T_{\text {ave }}=E T_{\text {sim }} /$ Area & $\begin{array}{l}E T_{\text {sim }} \text { is the simulated plant } \\
\text { evapotranspiration by WEP } \\
\text { model, Area is the study area }\end{array}$ \\
\hline & & $\begin{array}{l}\text { Annual runoff } \\
\text { variation coefficient }\end{array}$ & / & $C V=S D / M E A N$ & $\begin{array}{l}\mathrm{SD} \text { is the standard deviation of } \\
\text { runoff, MEAN is the mean runoff }\end{array}$ \\
\hline & \multirow[t]{2}{*}{$\begin{array}{l}\text { Ecological } \\
\text { support function }\end{array}$} & $\begin{array}{l}\text { Water conservation } \\
\text { function }\end{array}$ & $\begin{array}{l}\text { Water conservation } \\
\text { amount calculated based } \\
\text { on the water balance } \\
\text { method }\end{array}$ & $W=(R-E)^{\star} A$ & $\begin{array}{l}W \text { is the water conservation } \\
\text { amount, } R \text { is the precipitation, } E \\
\text { is the average } \\
\text { evapotranspiration, } A \text { is the total } \\
\text { area of the basin }\end{array}$ \\
\hline & & $\begin{array}{l}\text { Wind prevention and } \\
\text { sand fixation } \\
\text { function }\end{array}$ & $\begin{array}{l}\text { Compared with the } \\
\text { condition of no ecological } \\
\text { restoration, the } \\
\text { percentage of the area } \\
\text { converted from forest } \\
\text { land }\end{array}$ & $\begin{array}{l}\text { The area of cultivated land converted into } \\
\text { woodland and grassland is obtained } \\
\text { combining the land use transfer matrix }\end{array}$ & / \\
\hline & $\begin{array}{l}\text { Climate } \\
\text { regulation } \\
\text { function }\end{array}$ & $\begin{array}{l}\text { The total value of } \\
\text { ecological services } \\
\text { for climate regulation }\end{array}$ & $\begin{array}{l}\text { Estimated based on the } \\
\text { value of ecosystem } \\
\text { services per unit area }\end{array}$ & $C R V=\sum \sum\left(A_{k}^{*} C R_{f k}\right)$ & $\begin{array}{l}A_{k} \text { is the area of the kth land use } \\
\text { type, } C R_{f k} \text { is the value of } \\
\text { ecosystem service function of } \\
\text { the kth land use and fth function } \\
\text { for climate regulation }\end{array}$ \\
\hline & $\begin{array}{l}\text { Ecological } \\
\text { service function } \\
\text { serving the } \\
\text { economy and } \\
\text { society }\end{array}$ & $\begin{array}{l}\text { The value of } \\
\text { ecosystem services } \\
\text { that serve the } \\
\text { economic and social } \\
\text { aspects }\end{array}$ & / & $E S V=\sum \sum\left(A_{k} * V C_{f k}\right)$ & $\begin{array}{l}A_{k} \text { is the area of the kth land use } \\
\text { type, } V C_{f k} \text { is the value of } \\
\text { ecosystem service function of } \\
\text { the kth land use and the fth } \\
\text { function for economic and social } \\
\text { aspects }\end{array}$ \\
\hline $\begin{array}{l}\text { Functional } \\
\text { Coordination }\end{array}$ & $\begin{array}{l}\text { Coupling and } \\
\text { coordination }\end{array}$ & $\begin{array}{l}\text { The coordination } \\
\text { level among different } \\
\text { functions }\end{array}$ & / & $\begin{array}{l}D=\sqrt{C \cdot T} \\
C=\{F(x) G(y) /[(F(x)+G(y)) / 2] \hat{2}\} \hat{k} \\
T=\alpha F(x)+\beta G(y)\end{array}$ & $\begin{array}{l}D \text { is the coupling and } \\
\text { coordination, } C \text { is the } \\
\text { coordination, } T \text { is the } \\
\text { hydrological } \\
\text { regulation-ecological support } \\
\text { comprehensive evaluation index, } \\
F(x) \text { is the comprehensive } \\
\text { evaluation index of hydrological } \\
\text { regulation function, } G(y) \text { is the } \\
\text { comprehensive evaluation index } \\
\text { of ecological support function, } \\
k=2, \alpha=\beta=0.5\end{array}$ \\
\hline
\end{tabular}


TABLE 3 | Classification of coupling and coordination levels.

\begin{tabular}{|c|c|c|c|c|c|c|c|}
\hline Grades & $0-0.39$ & $0.4-0.49$ & $0.5-0.59$ & $0.6-0.69$ & $0.7-0.79$ & $0.8-0.89$ & $0.9-1$ \\
\hline $\begin{array}{l}\text { The coordination } \\
\text { level }\end{array}$ & Maladjustment & $\begin{array}{l}\text { On the verge of } \\
\text { maladjustment }\end{array}$ & $\begin{array}{l}\text { Constrainedly } \\
\text { coordinated }\end{array}$ & $\begin{array}{l}\text { Elementarily } \\
\text { coordinated }\end{array}$ & $\begin{array}{l}\text { Moderately } \\
\text { coordinated }\end{array}$ & $\begin{array}{l}\text { Well } \\
\text { coordinated }\end{array}$ & $\begin{array}{l}\text { Extremely } \\
\text { coordinated }\end{array}$ \\
\hline
\end{tabular}

TABLE 4 | Evaluation criteria for ecological restoration indicators on slopes.

First level Second level indicator
indicator

\section{Evaluation criteria (compared \\ with the stage \\ where slope ecological \\ restoration construction has \\ not yet been \\ carried out)}

Naturalness

Green area ratio

Biological abundance index

Ecological integrity

Functional types Annual plant transpiration per unit area

Annual runoff variation coefficient

Water conservation function

Wind prevention and sand fixation function

The total value of ecological services for climate regulation

Estimate the value of ecosystem services that serve the economic and social aspects

Functional coordination

The coordination level among different functions
The larger the green area ratio, the larger the scale of slope ecological restoration, and the more conducive to the improvement of naturalness

The larger the biological abundance index, the higher the biodiversity and the more perfect the ecological restoration composition of the slope

The landscape pattern indices generally develop toward decreasing trend of landscape fragmentation indicating that the ecological integrity is enhanced, and the ecological restoration quality is improved

Calculate the annual average plant transpiration per unit area from 1965 to 2017 and compare it with the frequency of incoming water to discover whether the ecological restoration construction on the slope can effectively improve the transpiration during the wet and dry years and enhance the effectiveness of hydrological regulation

The decrease in the variation coefficient of annual runoff from 1965 to 2017, reflecting the enhanced controllability of hydrological regulation functions

The larger the changes in water conservation amount, the stronger the water conservation function than before

The greater the percentage of forest land conversion area, the stronger the wind-proof and sand-fixing function than before

The greater the value of the climate regulation function, the stronger the climate regulation function

The greater the value of the ecological service function, the stronger the function

Evaluate the coupling coordination index of slope ecological restoration in different periods through the classification standard regulation function and ecological service function were calculated based on different types of land use. The functional coordination was evaluated from the degree of coordination between the functional types (Table 2). The classification of coupling and coordination levels is shown in Table 3 (He S., 2020). According to the entropy method, the normalization and weight determination were carried out, and the overall naturalness, functional types, and comprehensive evaluation index of the slope ecological restoration at different stages were obtained.

\section{(2) Evaluation standard}

According to the meanings of various indicators and the goal of slope ecological restoration construction, the evaluation criteria of various indicators of naturalness, function type, and function coordination were determined (Table 4).

\subsubsection{Configuration of slope ecological restoration based on watershed land suitability evaluation}

According to the land suitability evaluation system promulgated by the Food and Agriculture Organization of the United Nations in 1976 (Food and Agriculture Organization, 1976), an evaluation index system was established by considering factors such as DEM, precipitation, air temperature, soil, irrigation conditions, slope, and roughness. The weight and score of each index was determined and calculated based on the analytic hierarchy process. Combined with the geo-statistical classification method, the land suitability evaluation grade of each plot unit on the slope was obtained. Specifically, the evaluation methods of forest land and residential construction sites were as follows. According to the distribution of natural forest land, artificial forests and grasses (the sum of which are slope ecological restoration), the evaluation criteria, and grade of forest land were modified. Considering the urbanization process, the distribution range of counties and cities, the traditional evaluation criteria, and grade of residential construction sites were adjusted. Based on the evaluation results of the current status of land suitability, following the principles of "livability, cultivated land protection, forest protection, and grass regulation," the layout schemes of slope ecological restoration belonging to three suitability grades of general suitable $\left(\mathrm{S}_{\text {Low }}\right)$, 
TABLE 5 | Results of secondary evaluation indicators for slope ecological restoration at different construction stages.

\begin{tabular}{|c|c|c|c|c|c|}
\hline $\begin{array}{l}\text { First level } \\
\text { indicator }\end{array}$ & $\begin{array}{l}\text { Second level } \\
\text { indicator }\end{array}$ & S80 & S8000 & S0017 & S8017 \\
\hline \multirow[t]{10}{*}{ Naturalness } & Green area ratio & 0.1826 & 0.1829 & 0.4224 & 0.4226 \\
\hline & Biological abundance index & 105 & 105.1 & 124.4 & 124.9 \\
\hline & Number of patches & 5,155 & 5,119 & 39,930 & 42,069 \\
\hline & Largest patch index & 17.82 & 17.81 & 12.03 & 12.03 \\
\hline & Edge density & 28.28 & 28.25 & 42.69 & 43.45 \\
\hline & Average patch area & 301.80 & 303.93 & 38.96 & 36.98 \\
\hline & Area-weighted mean patch fractal dimension index & 1.28 & 1.28 & 1.26 & 1.26 \\
\hline & Contagion index & 58.27 & 58.28 & 53.75 & 53.49 \\
\hline & Shannon diversity index & 1.19 & 1.19 & 1.23 & 1.23 \\
\hline & Shannon evenness index & 0.66 & 0.66 & 0.69 & 0.69 \\
\hline \multirow[t]{6}{*}{ Functional types } & Annual plant transpiration per unit area & 0.0109 & 0.0116 & 0.0115 & 0.0118 \\
\hline & Annual runoff variation coefficient & 0.32 & 0.32 & 0.33 & 0.33 \\
\hline & Change ratio of water conservation amount & 0 & 0 & 0.03 & 0.01 \\
\hline & Percentage of converted forest land & 0 & 0 & 0.24 & 0.24 \\
\hline & The total value of ecological services for climate regulation & 20.96 & 20.98 & 28.87 & 28.85 \\
\hline & Estimate the value of ecosystem services that serve the economic and social aspects & 45.57 & 45.59 & 60.31 & 60.39 \\
\hline Functional coordination & The coordination level among different functions & 0.09 & 0.12 & 0.30 & 0.41 \\
\hline
\end{tabular}

Note. S80, S8000, S0017, and S8017 represent the slope ecological restoration in 1980, from 1980 to 2000 , from 2000 to 2017 , and from 1980 to 2017 respectively.

moderately suitable $\left(\mathrm{S}_{\mathrm{Med}}\right)$, and highly suitable $\left(\mathrm{S}_{\mathrm{High}}\right)$ were constructed with the goal of eliminating unsuitable plots and minimizing the area of critically suitable plots.

\subsubsection{Identifying the mitigation effects of different layout schemes on climate change}

Previous studies (Peng et al., 2015; Zhou et al., 2018; Li et al., 2019; Liu H. et al., 2020; Yang et al., 2020; Wang et al., 2021) verified the applicability of WEP model in different regions of China including the Huangshui River Basin (He S. et al., 2019). The meteorological data from the five general circulation models were integrated to a set of comprehensive climate model data based on an aforementioned research (He S. et al., 2019). The comprehensive climate model data and underlying surface scenarios were adopted to drive the distributed hydrological model (WEP) to obtain monthly runoff processes from 2021 to 2050 under different RCP scenarios. The change rates (e.g., $\left.\left(\mathrm{S}_{\text {Low }}-\mathrm{S}_{8017}\right) / \mathrm{S}_{8017}\right)$ of runoff and coefficient of variation (CV) of runoff under different layout schemes and current conditions $\left(\mathrm{S}_{8017}\right)$ were calculated in the whole hydrological period or in the wet, normal, and dry seasons. The mitigation effect of layout schemes of the slope ecological restoration on the extreme runoff process under future climate change was quantitatively identified.

\section{RESULTS}

\subsection{Historical evaluation of slope ecological restoration}

From the perspective of subfunctions, as the scale of slope ecological restoration increased, naturalness showed a trend of improvement, while the functional types decreased gradually before 2000, leading to a lower comprehensive evaluation index in 1980-2017 than that in 2000-2017. It may be due to the slight decrease in water conservation function index. That is
TABLE 6 | Comprehensive evaluation index results of slope ecological restoration at different construction stages.

\begin{tabular}{lcccc}
\hline Evaluation index & $\mathbf{S 8 0}$ & $\mathbf{S 8 0 0 0}$ & $\mathbf{s 0 0 1 7}$ & $\mathbf{S 8 0 1 7}$ \\
\hline Naturalness & 0.25 & 0.25 & 0.38 & 0.38 \\
Functional types & 0.04 & 0.03 & 0.31 & 0.27 \\
Functional coordination & 0 & 0.01 & 0.03 & 0.05 \\
Comprehensive evaluation index & 0.29 & 0.28 & 0.72 & 0.70 \\
\hline
\end{tabular}

Note. Optimal allocation of slope ecological restoration

because annual evapotranspiration in 2000-2017 was higher than that in 1980-2017 (Table 5). This indicated that the current slope ecological restoration needed to be further configured and improved both for the comprehensive evaluation index and the individual functions to ensure the improvement of overall function of the basin. The results of the comprehensive evaluation index showed that as the scale of slope ecological restoration increases, the comprehensive functions were gradually improved, especially after 2000 (Table 6).

\subsection{Optimal allocation of slope ecological restoration \\ 3.2.1 Evaluation of current land suitability in the watershed}

In general, the proportions of highly suitable, moderately suitable, generally suitable, critically suitable, and unsuitable areas in the Huangshui Basin were $14.3 \%, 21.1 \%, 40.9 \%, 21.2 \%$, and $2.5 \%$, respectively. In terms of spatial distribution, the valley areas in the middle and lower reaches of the main stream of the Huangshui River Basin belonged to highly suitable, moderately suitable, and generally suitable grades. The mountainous areas on both sides and the southwestern mountainous areas were mainly classified as critically suitable and unsuitable grades (Figure 3). From the 


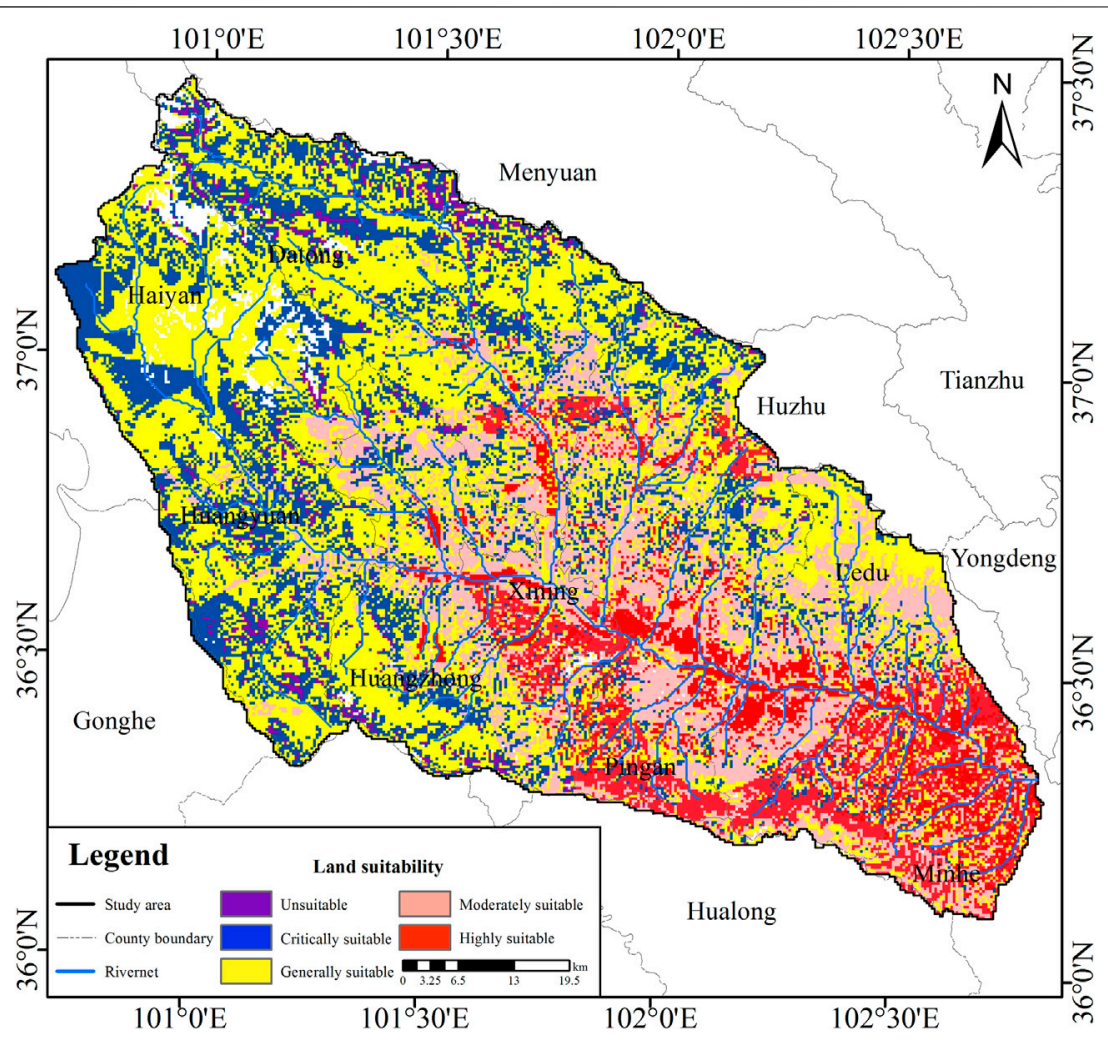

FIGURE 3 | Overall land suitability grade map of the Huangshui River Basin.

perspective of land use, the high suitability grade area of forest land accounted for $17.27 \%$ of the total area; followed by residential and construction land, and grassland for $16.37 \%$ and $15.42 \%$, respectively. The proportion of high suitability grade area of cultivated land was only $7.2 \%$, and the sum of general suitability and critical suitability accounts for $97.92 \%$.

\subsubsection{Layout scheme of slope ecological restoration}

Compared with the evaluation results of 2017, the forestland area increased by $3,450.73 \mathrm{~km}^{2}$, and the grassland area decreased by $3,450.73 \mathrm{~km}^{2}$ in the highly suitable scheme $\left(\mathrm{S}_{\mathrm{High}}\right)$. The forestland increased by $1,735.06 \mathrm{~km}^{2}$, and the grassland decreased by $1,735.06 \mathrm{~km}^{2}$ in the moderately suitable scheme $\left(\mathrm{S}_{\mathrm{Med}}\right)$. The forestland decreased by $554.213 \mathrm{~km}^{2}$ and the grassland increased by $554.213 \mathrm{~km}^{2}$ in the generally suitable scheme $\left(\mathrm{S}_{\text {Low }}\right)$ (Figure 4).

\subsection{Evaluation of layout schemes of slope ecological restoration}

Compared with S8017, most indices of the naturalness and functionality of the three slope ecological restoration layout schemes were enhanced. The coupling coordination degree indices showed growing trends, especially the $\mathrm{S}_{\mathrm{High}}$ scheme with an increase by $84.3 \%$. According to the evaluation criteria of the coupling coordination degree, the coordination between functional types of the three schemes were close to the constrainedly coordinated (Table 3). The complete imbalance state of current situation was changed, and the overall functional coordination was enhanced (Table 7).

\subsection{Mitigation effect of layout schemes on climate change}

The simulated runoff at Xinachuan, Qiaotou, Xining, and Minhe Stations matched well with the observation. The Nash coefficients exceeded 0.55 , the correlation coefficients exceeded 0.75 , and the relative errors were about $15 \%$ during the calibration period. The Nash coefficients were above 0.5 , the correlation coefficients were about 0.7 , and the relative errors were about $15 \%$ during the verification period (He S. et al., 2019). The simulated runoff by the WEP model was used for further analysis.

\subsubsection{Relative change rate of runoff}

From 2021 to 2050, the change rates of the runoff under different layout schemes relative to $\$ 8017$ were calculated (Figure 5). As shown in Figure 5A, in the same RCP scenario, the annual average runoff under the three layout schemes all increased by about $10 \%$ compared with the current runoff volume. From the perspective of different periods, the runoff during the wet season can effectively be reduced by about $20 \%$ under the three layout schemes. The reduction effects of $\mathrm{S}_{\mathrm{High}}$ scheme were particularly obvious, and the effects were enhanced with the increase in 

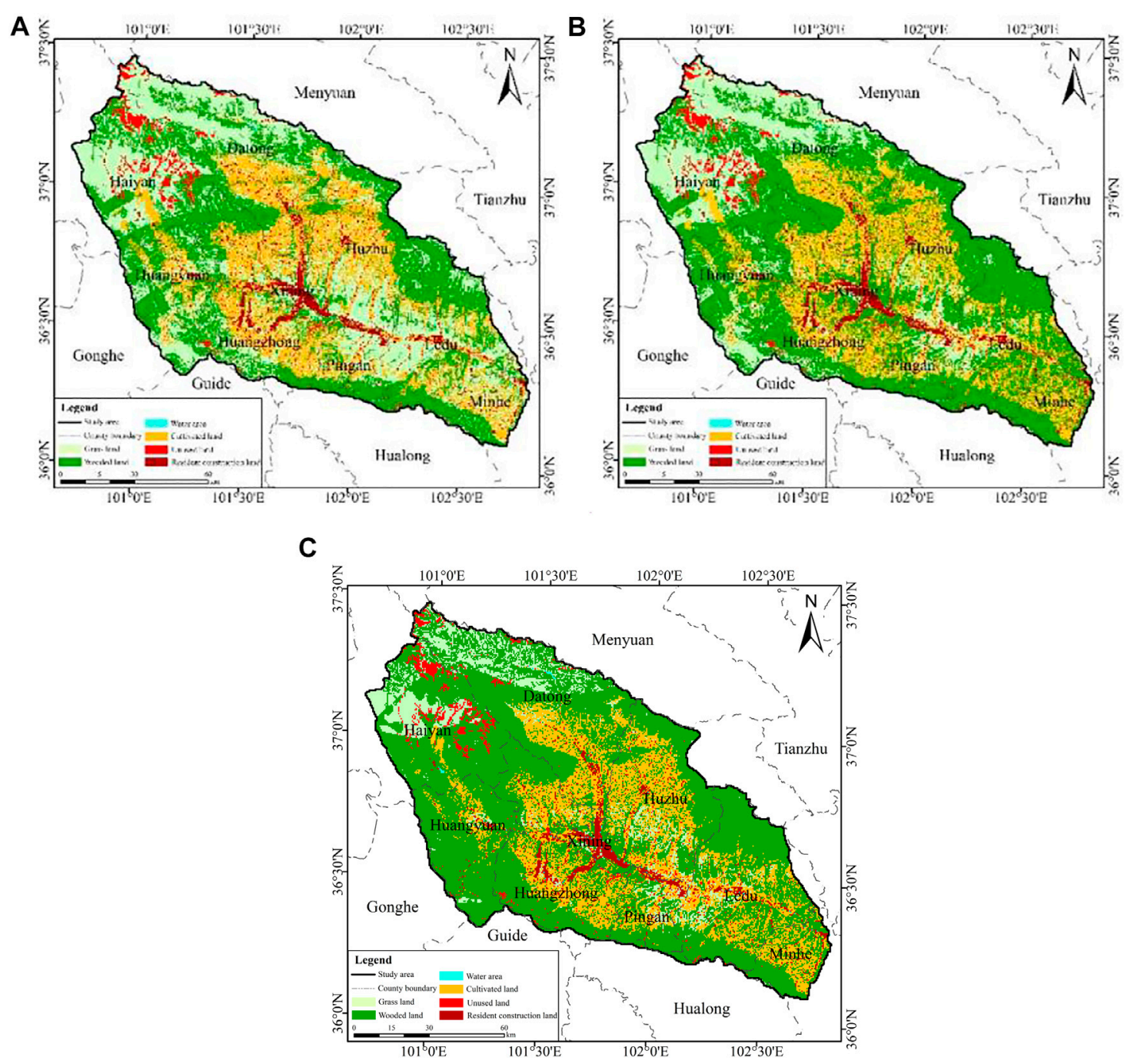

FIGURE 4 | Different levels of layout schemes of slope ecological restoration: (A) generally suitable, (B) moderately suitable and (C) highly suitable.

emission concentration under different climate scenarios. The runoff was reduced by about $30 \%$ under the scenario RCP8.5. During the normal and dry seasons, the runoff increased significantly, which effectively supplemented the insufficient flow during the dry season under future climate change, and improved the regional water conservation capacity.

\subsubsection{Runoff variability}

In the same RCP scenario, the $\mathrm{CV}$ values of the annual runoff decreased under the three layout schemes compared with that under current slope ecological restoration at seven typical hydrological stations except for Chaoyang Station, especially for the $\mathrm{S}_{\text {High }}$ scheme with a reduction of about 60\% (Figure 6). Under different RCP scenarios, the CV value of annual runoff under current slope ecological restoration gradually decreased as the emission concentration increased at seven typical hydrological stations except for Minhe Station.

In different hydrological periods, the influences of three layout schemes on CV values of runoff varied. During the wet seasons, the influences showed similar patterns with that in the annual scale. In the normal seasons, the CV values of the runoff decreased under the three layout schemes (compared with the current slope ecological restoration) at all seven typical hydrological stations. During the dry seasons, most stations showed the decreasing trend of CV of runoff under the three layout schemes (compared with the current slope ecological restoration) except for Baliqiao Station.

As for the influences under different climate scenarios, different hydrological seasons showed different patterns (Figure 7). During the wet seasons, the $\mathrm{CV}$ values of runoff under RCP 4.5 were the largest compared with those under RCP 2.6 and RCP 8.5 at most stations. In the normal seasons, the $\mathrm{CV}$ values of runoff under RCP 2.6 were the largest compared with those under RCP 4.5 and RCP 8.5 at most stations. During the dry seasons, the changes in CV values of runoff under layout schemes were not the same with that under the current slope ecological restoration. Under the current slope ecological restoration, most stations showed the largest CV under RCP4.5 compared with those under RCP 2.6 and RCP 8.5, while under the three layout schemes, the largest CV appeared under RCP2.6 compared with those of other climate scenarios at most stations. 
TABLE 7 | Evaluation results of individual indicators for different layout allocation schemes of slope ecological restoration.

\begin{tabular}{|c|c|c|c|c|c|}
\hline $\begin{array}{l}\text { First level } \\
\text { indicator }\end{array}$ & $\begin{array}{l}\text { Second level } \\
\text { indicator }\end{array}$ & S8017 & $\mathrm{S}_{\text {Low }}$ & $\mathbf{S}_{\text {Med }}$ & $\mathrm{S}_{\mathrm{High}}$ \\
\hline \multirow[t]{10}{*}{ Naturalness } & Green area ratio & 0.42 & 0.37 & 0.53 & 0.66 \\
\hline & Biological abundance index & 124.9 & 115.9 & 126.4 & 134.7 \\
\hline & Number of patches & 42,069 & 4,166 & 3,631 & 3,381 \\
\hline & Largest patch index & 12.03 & 14.62 & 39.63 & 55.21 \\
\hline & Edge density & 43.45 & 14.28 & 12.73 & 11.28 \\
\hline & Average patch area & 36.98 & 373.46 & 428.48 & 460.17 \\
\hline & Area-weighted mean patch fractal dimension index & 1.26 & 1.22 & 1.24 & 1.24 \\
\hline & Contagion index & 53.49 & 58.18 & 60.32 & 65.02 \\
\hline & Shannon diversity index & 1.23 & 1.31 & 1.25 & 1.1 \\
\hline & Shannon evenness index & 0.69 & 0.73 & 0.70 & 0.61 \\
\hline \multirow[t]{6}{*}{ Functional types } & Annual plant transpiration per unit area & 0.01 & 0.01 & 0.01 & 0.01 \\
\hline & Annual runoff variation coefficient & 0.33 & 0.29 & 0.29 & 0.29 \\
\hline & Change ratio of water conservation amount & 0 & 0.14 & 0.22 & 0.22 \\
\hline & Percentage of converted forest land & 0 & -0.07 & 0.07 & 0.19 \\
\hline & The total value of ecological services for climate regulation & 28.85 & 26.29 & 31.04 & 34.79 \\
\hline & $\begin{array}{l}\text { Estimate the value of ecosystem services that serve the } \\
\text { economic and social aspects }\end{array}$ & 60.39 & 60.11 & 69.58 & 77.06 \\
\hline Functional coordination & The coordination level among different functions & 0.32 & 0.39 & 0.47 & 0.59 \\
\hline
\end{tabular}
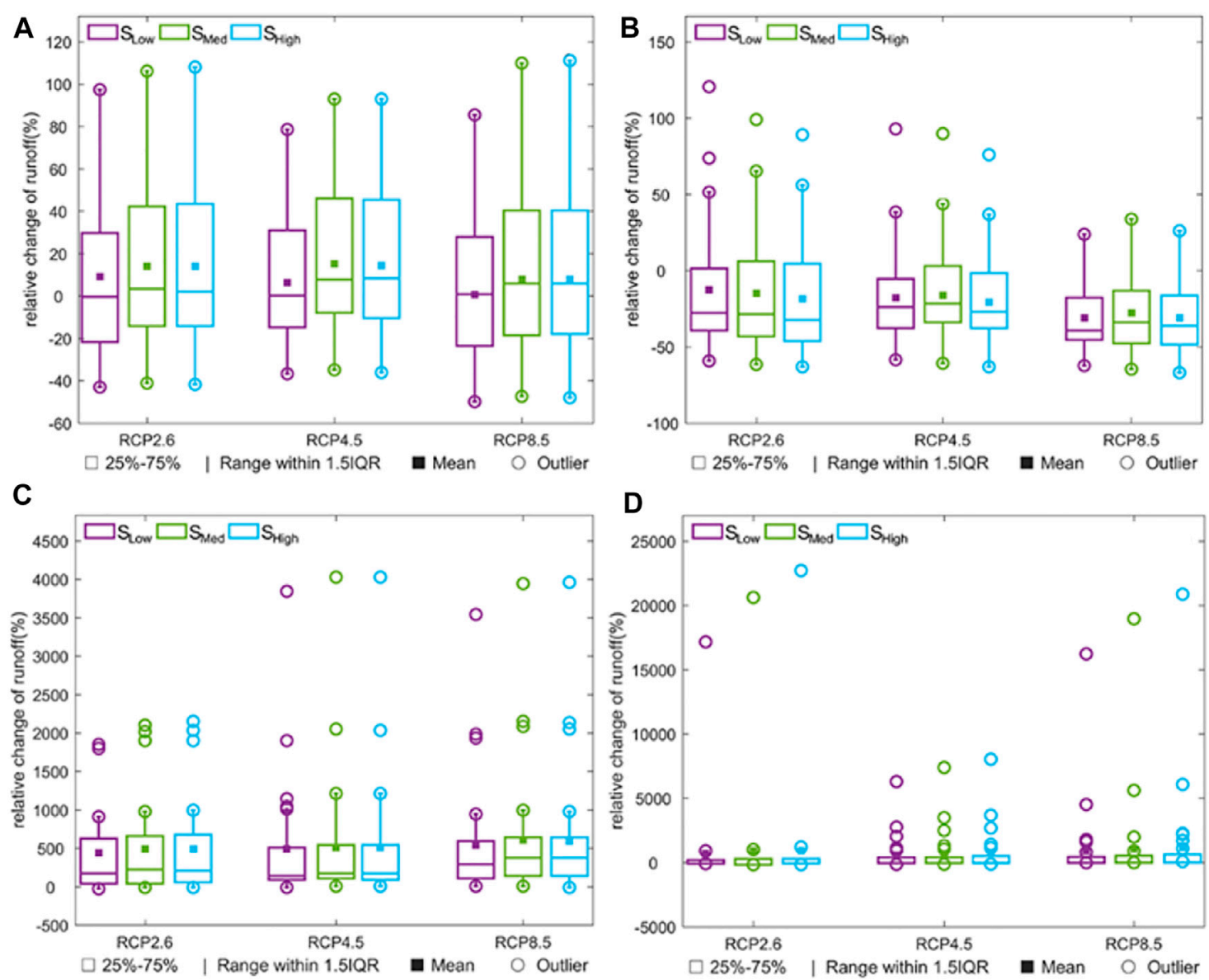

FIGURE 5 | Box diagram of the relative changes of annual average/seasonal runoff of different layout schemes in 2021-2050 in the Huangshui River Basin under future climate scenarios: (A) represents annual pattern, (B) represents the pattern in wet season, (C) represents the pattern in normal season, (D) represents the pattern in dry season. The small rectangles in purple, green and blue represent the $25 \%$ to $75 \%$ quantiles of relative changes of annual(seasonal) average runoff. I (range within $1.5 \mathrm{IQR}$ ) represents one and a half times the quartile distance. The black solid box represents the mean value. Open squares indicate outliers. 


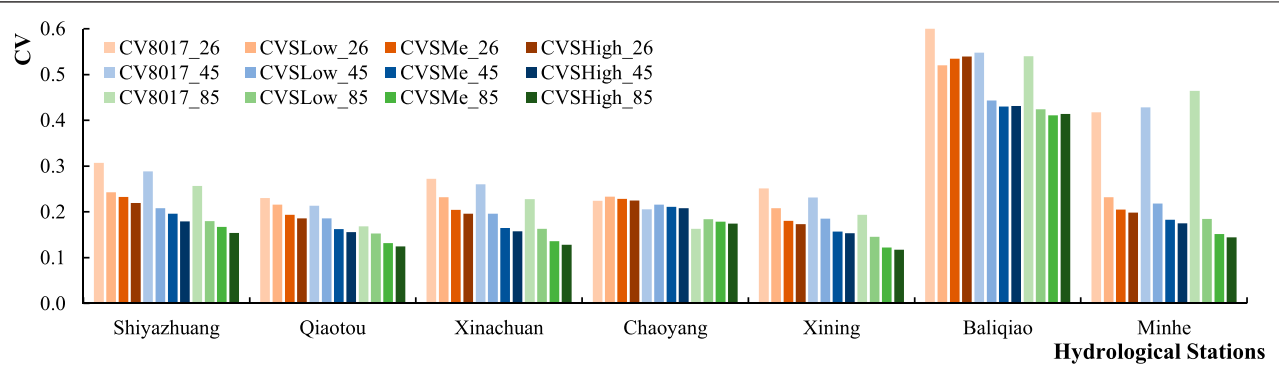

FIGURE 6 | Changes in the coefficient of variation (CV) values of annual runoff under different layout schemes and different climate scenarios.

$\mathbf{z}$

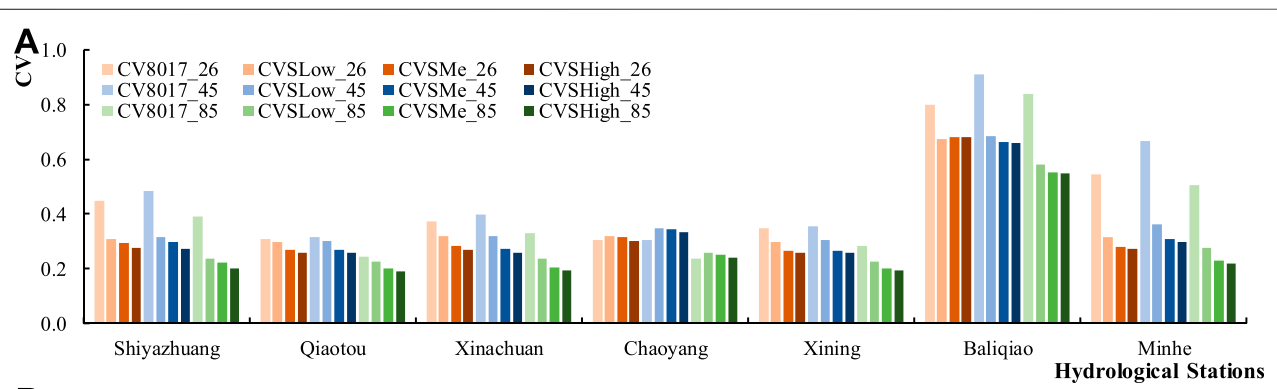

B

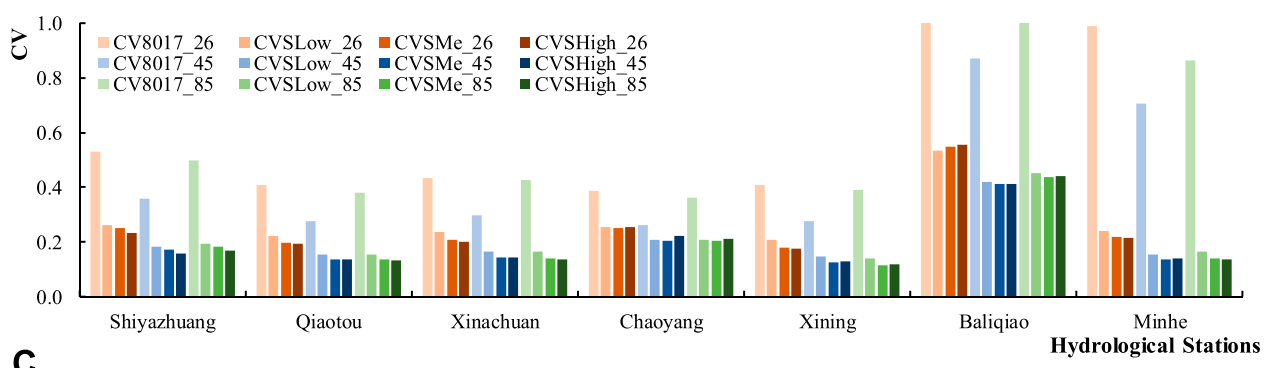

C

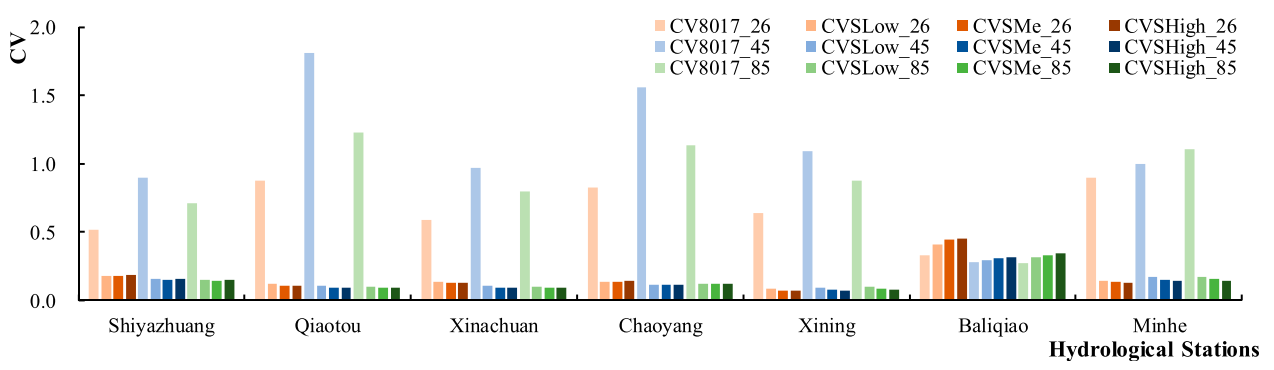

FIGURE 7 | The CV values of runoff in different hydrological periods under different layout schemes and different climate scenarios (A-C) represents the wet seasons, the normal seasons, and the dry seasons, respectively. CV8017_26/45/85 represents the variation coefficient of runoff in each hydrological period with the current slope ecological restoration under the emission scenarios of low-emission scenario (RCP2.6), medium-emission scenario (RCP4.5), and high-emission scenario (RCP8.5), respectively; CVSLow_26/45/85 represents the variation coefficient of runoff in each hydrological period with the layout schemes of slope ecological restoration at generally suitable grade under the emission scenarios of RCP2.6, RCP4.5, and RCP8.5; CVSMe_26/45/85 represents the variation coefficient of runoff in each hydrological period with the layout schemes of slope ecological restoration at moderately suitable grade under the emission scenarios of RCP2.6, RCP4.5, and RCP8.5; CVSHigh_26/45/85 represents the variation coefficient of runoff in each hydrological period with the layout schemes of slope ecological restoration at highly suitable grade under the emission scenarios of RCP2.6, RCP4.5, and RCP8.5, respectively.

\subsection{Selection of the optimal layout scheme}

The $S_{\text {High }}$ scheme has the highest score in the comprehensive evaluation index of all layout schemes (Table 8), which indicated that this scheme meets the needs of a new mode for basin water governance typically for naturalness and functional coordination. Combined with analysis of different layout schemes for future climate change mitigation, this scheme has the most obvious effect on avoiding extreme hydrological events. Therefore, the 
TABLE 8 | Comprehensive evaluation index results.

\begin{tabular}{lcccc}
\hline Evaluation index & $\mathbf{S 8 0 1 7}$ & $\mathbf{S}_{\text {Low }}$ & $\mathbf{S}_{\text {Med }}$ & $\mathbf{S}_{\text {High }}$ \\
\hline Naturalness & 0.26 & 0.26 & 0.28 & 0.37 \\
Functional types & 0.1 & 0.09 & 0.19 & 0.29 \\
Functional coordination & 0.01 & 0.02 & 0.03 & 0.06 \\
Comprehensive evaluation index & 0.37 & 0.37 & 0.50 & 0.71 \\
\hline
\end{tabular}

$\mathrm{S}_{\mathrm{High}}$ scheme is determined as the optimal layout scheme for the slope ecological restoration construction in the Huangshui River Basin. The plan is to adjust the unsuitable grades of residential construction sites and arable land to general suitable grades, and the areas suitable for forestry and grass will be developed as forest land.

\section{DISCUSSIONS}

\subsection{Impact of slope ecological restoration scale on historical evaluation}

From the perspective of Naturalness, S8000 had no obvious impacts on the indicators compared with S80. Compared with S80 and S8000, the ecological restoration scale and the biological abundance index under S0017 and S8017 increased. This is mainly concerned with the implementation of a series of ecological restoration projects including natural reserves, national forest park, and large-scale forest farms in the Huangshui River Basin since the 1970s (Sun et al., 2015; Zhang Y. et al., 2016; Forestry and Grassland Bureau of Qinghai, 2018; Treacy et al., 2018; Feng et al., 2021). As the scale of ecological restoration has increased significantly, the landscape pattern indices, such as number of patches, edge density, Shannon diversity index, and Shannon evenness index increased, and the largest patch index, average patch area, area-weighted mean patch fractal dimension index, and contagion index decreased. The overall naturalness of the basin increased. While due to the discrete distribution and homogeneity of such ecological restoration measures, the landscape pattern index shows an increasing trend in number of patches, diversity, and fragmentation.

Referring to the indicators of function types, S8000 had no obvious impacts on them compared with S80. Annual plant transpiration per unit area under S0017 and S8017 has slightly increase compared with that under S80. The underlying mechanism maybe complex. On the one hand, the study area experiences an arid and semi-arid continental climate, and continuous drought in spring and summer occurs in $40 \%$ of the years. The background value of evapotranspiration per unit area is low (Zhang C. et al., 2016; Li et al., 2020). On the other hand, the growth of vegetation in the study area depends on artificial irrigation, and the local water resources are scarce, which limit the water used for irrigation. The growth of vegetation is mainly restricted by artificial irrigation along the river and from reservoirs, and snowmelt-runoff irrigation (Kou et al., 2021). When the scale of ecological restoration is expanded, annual plant transpiration per unit area will not increase much. Annual runoff variation coefficient under S0017 and S8017 has little changes compared with that under S80 and S8000. In normal seasons, the runoff $\mathrm{CV}$ in most hydrological stations all decreased except for the slight increase at the Baliqiao station. In dry seasons, the runoff $\mathrm{CV}$ at the Xinachuan station increased slightly, with the rest of the hydrological stations decreasing. The effects of slope ecological restoration on runoff $\mathrm{CV}$ in wet seasons are spatially inconsistent. Comprehensive influence of the three seasons explains the slight change in annual runoff variation coefficient under S0017 and S8017 compared with that under S80 (He S. et al., 2019). Moreover, the upstream areas of Qiaotou and Chaoyang Stations are alpine regions and covered with snow and ice. After forest disturbances, greater snow accumulation is estimated (melting earlier and faster) (Winkler et al., 2005), and melt ice and snow during wet seasons replenish runoff, which lead to the insignificant reduction in runoff variation coefficient.

With the expansion of scale of ecological restoration and enrichment of composition, the structure and function of ecosystems changed, and the water conservation function, wind prevention, and sand fixation function, ecological services for climate regulation and those serving the economic and social aspects have been significantly enhanced, and the function type indicators have been improved overall, which were similar to the conclusions of other scholars (Tang et al., 2014; Angela et al., 2015; Xu et al., 2019; Zhou 2019). Functional types increased, functional coordination increased, and comprehensive evaluation index increased significantly. We also propose that increasing tree species diversity which will positively affect soil functioning (e.g., soil biodiversity, nutrient availability), the resilience of the forest ecosystem, and the ecological service functions of watersheds (Vicente-Vicente et al., 2019).

As the scale of slope ecological restoration increased (S8017 compared with S0017), the complexity of ecosystem composition increased, the diversity of landscape patterns were enhanced, and the degree of patch aggregation decreased. The overall functional type index showed a decreasing trend after 2000. Two reasons may be related to phenomenon. Ecological restoration measures in the Huangshui River Basin were scattered, and the types of artificial forests were homogeneous. Although the scale of ecological restoration has expanded, the improvement of ecological service functions was limited. After 2000, due to the reduction in water conservation function and climate regulation function, the overall function type index of S8017 was lower than that of S0017. Although functional type index decreased, functional coordination enhanced with the increase in slope ecological restoration scale, which indicated that the coordination between hydrological adjustment and ecological support functions were improved. The comprehensive evaluation index decreased. This phenomenon indicates that the slope ecological restoration needs to further refine the layout schemes and pay more attention to the simultaneous improvement of the comprehensive evaluation index and the individual evaluation index.

\subsection{Mitigation effect of layout schemes on climate change}

Under RCP2.6, RCP4.5, RCP8.5 climate scenarios, the impacts of layout schemes on relative change rate of runoff at different time scales varied. The relative change rates of annual average runoff and of runoff in the normal and dry seasons were positive, while 
the relative change rates of runoff during the wet season were negative. This phenomenon indicates that the layout schemes of slope ecological restoration can effectively reduce the peak flow and increase the dry season runoff under future extreme climate scenarios. The impacts of slope ecological restoration on reduction of runoff in wet seasons and supplement in dry seasons can be demonstrated by relevant studies (Hou et al., 2018; Takata and Hanasaki, 2020), which reduce flood potentials in the wet season and drought severity in the dry season (Guo et al., 2008). As Bosch J.M. and Hewlett J.D. (Bosch and Hewlett, 1982) inferred, coniferous forest, deciduous hardwood, shrub, and grassland have (in that order) a decreasing influence on water yield of the basin in which these covers are manipulated. Therefore, regulation of forest land may be the key to the optimal layout of slope ecological restoration.

At Chaoyang Station, there was little difference between the $\mathrm{CV}$ values of the annual runoff under three layout schemes and that under current slope ecological restoration, which indicated that the three layout schemes have relatively less impacts on the runoff variability at the Chaoyang Station. This may be due to the fact that Chaoyang Station is located in the middle reaches of the Huangshui River Basin, and the three layout schemes have relatively small differences in the sub-basin area controlled by Chaoyang Station. Hence, annual runoff variability is significantly affected by climate change.

The differences in the CV value of annual runoff under current slope ecological restoration at Minhe Station may be concerned with its location. Minhe Station is located at the exit of the Huangshui River Basin. Under the current slope ecological restoration, its annual runoff $\mathrm{CV}$ increases with the increase in the emission concentration of the climate scenario, while the annual runoff $\mathrm{CV}$ under the three layout schemes decreases as the emission concentration increases.

Except for Chaoyang and Baliqiao stations, the $S_{\text {High }}$ scheme at most stations has significant reduction effect on the $\mathrm{CV}$ value of annual runoff. We concluded that $\mathrm{S}_{\mathrm{High}}$ reduced the occurence of extreme water conditions in wet and dry seasons and effectively increased the stability of the annual runoff (Xu Z. et al., 2021).

The decreasing trends of the three layout schemes in the wet and normal seasons are similar with the results of $\mathrm{Xu} \mathrm{Z}$. et al. (2021). In general, the three layout schemes of slope ecological restoration have significantly reduced the variability of runoff processes in the entire watershed, at different stations and in different hydrological periods. The layout schemes have also avoided extreme hydrological events, and effectively mitigated the negative effects of climate change.

\section{CONCLUSION}

Based on the naturalness, functional types, and functional coordination, the evaluation index system of slope ecological restoration was constructed. The individual index at different historical stages was analyzed, and the entropy method was used to calculate the comprehensive evaluation index. The results showed that as the scale of slope ecological restoration increased, the comprehensive functions were improved gradually, the naturalness and functional types were gradually improved, and the functional coordination was gradually better.

According to the evaluation results of the current status of land suitability, following the principles of "livability, cultivated land protection, forest protection, and grass regulation," the layout schemes of slope ecological restoration belonging to three suitability grades of general suitable $\left(S_{\text {Low }}\right)$, moderately suitable $\left(\mathrm{S}_{\mathrm{Med}}\right)$, and highly suitable $\left(\mathrm{S}_{\mathrm{High}}\right)$ were constructed with the goal of eliminating unsuitable plots and minimizing the area of critically suitable plots.

On the one hand, the optimized configuration of slope ecological restoration will have the effect of "cutting peaks and replenishing dryness," which significantly reduce the extreme impact of future climate change. On the other hand, it can also exert the naturalness and functional coordination of slope ecological restoration to provide reference for the future watershed governance mode.

In this study, a comprehensive Evaluation Index System of slope ecological restoration was developed, among which, hydrologic regulation function and ecological support function were considered. With the in-depth identification of the impact mechanism of slope ecological restoration on the process of slope runoff generation in the future, the evaluation system needs to be further enriched and improved.

\section{DATA AVAILABILITY STATEMENT}

The original contributions presented in the study are included in the article/Supplementary Material. Further inquiries can be directed to the corresponding authors.

\section{AUTHOR CONTRIBUTIONS}

TQ wrote the original draft of this manuscript. SH and SL designed the manuscript. $\mathrm{HN}$ and $\mathrm{BD}$ undertook the analysis of data. XL revised the manuscript.

\section{FUNDING}

This research was supported by the National Key Scientific Instrument and Equipment Development Projects of China (Grant No. 2017YFA0605004), the China National Science Funds for Distinguished Young Scientists (Grant No. 51725905), the National Science Fund Project (Grant No. 51879275), and the Talent Supporting Program of China Institute of Water Resources and Hydropower Research (Grant No. WR0199A012021).

\section{ACKNOWLEDGMENTS}

We thank the data observers for their hard work. 


\section{REFERENCES}

Amenu, G. G., and Kumar, P. (2008). A Model for Hydraulic Redistribution Incorporating Coupled Soil-Root Moisture Transport. Hydrol. Earth Syst. Sci. 12, 55-74. doi:10.5194/hess-12-55-2008

Angela, C.-B., Javier, C.-J., Teresa, G.-M., and Marisa, M.-H. (2015). Hydrological Evaluation of a Peri-Urban Stream and its Impact on Ecosystem Services Potential. Glob. Ecol. Conservation 3, 628-644. doi:10.1016/j.gecco.2015.02.008

Bai, P., Liu, X., Zhang, Y., and Liu, C. (2020). Assessing the Impacts of Vegetation Greenness Change on Evapotranspiration and Water Yield in China. Water Resour. Res. 56, e2019WR027019. doi:10.1029/2019WR027019

Bo, L., Li, Z., Li, P., Xu, G., Xiao, L., and Ma, B. (2021). Soil Freeze-Thaw and Water Transport Characteristics under Different Vegetation Types in Seasonal FreezeThaw Areas of the Loess Plateau. Front. Earth Sci. 9, 704901. doi:10.3389/feart. 2021.704901

Bosch, J. M., and Hewlett, J. D. (1982). A Review of Catchment Experiments to Determine the Effect of Vegetation Changes on Water Yield and Evapotranspiration. J. Hydrol. 55 (1-4), 3-23. doi:10.1016/0022-1694(82) 90117-2

Chong-Hai, X., and Ying, X. (2012). The Projection of Temperature and Precipitation over China under RCP Scenarios Using a CMIP5 Multi-Model Ensemble. Atmos. Oceanic Sci. Lett. 5, 527-533. doi:10.1080/16742834.2012. 11447042

Dong, B., Qin, T., Liu, S., Liu, F., Nie, H., Wang, J., et al. (2021). Disentangling the Mutual Feedback Relationship between Extreme Drought and Flood Events and Ecological Succession of Vegetation. Pol. J. Environ. Stud. 30, 1003-1016. doi:10.15244/pjoes/124118

Eichner, T., and Tschirhart, J. (2007). Efficient Ecosystem Services and Naturalness in an Ecological/economic Model. Environ. Resource Econ. 37, 733-755. doi:10. 1007/s10640-006-9065-4

Fathizadeh, O., Hosseini, S. M., Zimmermann, A., Keim, R. F., and Bolooranid, A. D. (2017). Estimating Linkages between forest Structural Variables and Rainfall Interception Parameters in Semi-arid Deciduous oak forest Stands. Sci. Total Environ. 601, 1824-1837. doi:10.1016/j.scitotenv.2017.05.233

Feng, J., Dong, B., Qin, T., Liu, S., Zhang, J., and Gong, X. (2021). Temporal and Spatial Variation Characteristics of NDVI and its Relationship with Environmental Factors in Huangshui River Basin from 2000 to 2018. Pol. J. Environ. Stud. 30, 3043-3063. doi:10.15244/pjoes/130517

Feng, S. C., Gao, X. H., Gu, J., Kang, J., Guo, L. F., Wu, G. L., et al. (2013). Land Use Spatial Distribution Modeling Based on Clue-S Model in the Huangshui River Basin. Acta Eco Sin 33, 985-997. doi:10.5846/stxb201204280616

Food and Agriculture Organization (1976). A Framework for Land Evaluation, 52. Rome: FAO Soils Bulletin.

Forestry and Grassland Bureau of Qinghai (2018). Pilot Plan for Large-Scale woodland Construction (2018-2025). Huangshui, Qinghai Province: Forestry and Grassland Bureau of Qinghai.

Ghimire, C. P., Adrian Bruijnzeel, L., Lubczynski, M. W., Ravelona, M., Zwartendijk, B. W., and van Meerveld, H. J. (2017). Measurement and Modeling of Rainfall Interception by Two Differently Aged Secondary Forests in upland Eastern Madagascar. J. Hydrol. 545, 212-225. doi:10.1016/ j.jhydrol.2016.10.032

Guo, H., Hu, Q., and Jiang, T. (2008). Annual and Seasonal Streamflow Responses to Climate and Land-Cover Changes in the Poyang Lake basin, China. J. Hydrol. 355, 106-122. doi:10.1016/j.jhydrol.2008.03.020

He, S. (2020). Optimal Allocation of Slope Green Infrastructure in the Huangshui River basin. Beijing: China Institute of Water Resources and Hydropower Research.

He, S., Qin, T., Liu, F., Liu, S., Dong, B., Wang, J., et al. (2019). Effects of Slope Ecological Restoration on Runoff and its Response to Climate Change. Ijerph 16, 4017. doi:10.3390/ijerph16204017

He, Z., Shang, X., and Zhang, T. (2019). Spatiotemporal Evaluation and Driving Mechanism of Land Ecological Security in Yan'an, a Typical Hill-Gully Region of China's Loess Plateau, from 2000 to 2018. Forests 12, 1754. doi:10.3390/ f12121754

Hou, Y., Zhang, M., Meng, Z., Liu, S., Sun, P., and Yang, T. (2018). Assessing the Impact of Forest Change and Climate Variability on Dry Season Runoff by an Improved Single Watershed Approach: A Comparative Study in Two Large Watersheds, China. Forests 9, 46. doi:10.3390/f9010046
Hua, W., Chen, H., and Li, X. (2015). Effects of Future Land Use Change on the Regional Climate in China. Sci. China Earth Sci. 58, 1840-1848. doi:10.1007/ s11430-015-5082-x

Huang, Z., Tian, F. P., Wu, G. L., Liu, Y., and Dang, Z. Q. (2017). Legume Grasslands Promote Precipitation Infiltration Better Than Gramineous Grasslands in Arid Regions. Land Degrad. Develop. 28, 309-316. doi:10. 1002/ldr.2635

IPCC (2014). Climate Change, 2014, Synthesis Report. Britain: IPCC.

IPCC (2012). Managing-The-Risks Adaptation. A Special Report of Working, Groups I and II of the Intergovernmental Panel on Climate Change. Britain: IPCC.

Jiang, C. B., Li, J. K., Gao, J. Y., Lv, P., Yao, S. T., and Li, H. E. (2021). Research Progress of Grey-green Rainwater Infrastructure Optimal Configuration in Sponge City Construction. J. Hydroelectric Eng. 40, 1-12. doi:10.11660/slfdxb. 20210302

Jin, K., Wang, F., Zong, Q., Qin, P., and Liu, C. (2020). Impact of Variations in Vegetation on Surface Air Temperature Change over the Chinese Loess Plateau. Sci. Total Environ. 716, 136967. doi:10.1016/j.scitotenv.2020.136967

Kou, P., Xu, Q., Jin, Z., Yunus, A. P., Luo, X., and Liu, M. (2021). Complex Anthropogenic Interaction on Vegetation Greening in the Chinese Loess Plateau. Sci. Total Environ. 778, 146065. doi:10.1016/j.scitotenv.2021.146065

Li, J., Zhou, Z., Wang, H., Liu, J., Jia, Y., Hu, P., et al. (2019). Development of WEPCOR Model to Simulate Land Surface Water and Energy Budgets in a Cold Region. Nordic Hydrol. 50, 99-116. doi:10.2166/nh.2017.032

Li, R., Zheng, H., Lv, S., Liao, W., and Lu, F. (2018). Development and Evaluation of a New index to Assess Hydrologic Regulating Service at Sub-watershed Scale. Ecol. Indicators 86, 9-17. doi:10.1016/j.ecolind.2017.12.023

Li, S., Liang, W., Fu, B., Lü, Y., Fu, S., Wang, S., et al. (2016). Vegetation Changes in Recent Large-Scale Ecological Restoration Projects and Subsequent Impact on Water Resources in China's Loess Plateau. Sci. Total Environ. 569-570, 1032-1039. doi:10.1016/j.scitotenv.2016.06.141

Li, W. J., and Li, J. F. (2019b). Identification and Optimization of Small and Medium-Sized Green Infrastructure Based on GIS: A Case Study of Nanxi Wetland Ecological Tourist Area in Xuancheng, Anhui Province. J. Hefei Univ. Tech. (Social Science) 31, 128-134.

Li, X., Zhang, X., and Zhang, L. (2017c). Observed Effects of Vegetation Growth on Temperature in the Early Summer over the Northeast China Plain. Atmosphere 8, 97. doi:10.3390/atmos8060097

Li, Y., Ma, Q. W., and Fan, X. Y. (2017a). Delimiting the Urban Ecological Belts Based on green Infrastructure Assessment: A Case Study of Hangzhou. Geographical Res. 36, 583-591. doi:10.11821/dlyj201703015

Li, Z., Liu, P., Feng, M., Cui, X., He, P., Wang, C., et al. (2020). Evaluating the Effect of Transpiration in Hydrologic Model Simulation through Parameter Calibration. J. Hydrol. Eng. 25, 04020007. doi:10.1061/(asce)he.1943-5584.0001895

Li, Z., Liu, W.-z., Zhang, X.-c., and Zheng, F.-l. (2009). Impacts of Land Use Change and Climate Variability on Hydrology in an Agricultural Catchment on the Loess Plateau of China. J. Hydrol. 377, 35-42. doi:10.1016/j.jhydrol.2009.08.007

Liu, F., Qin, T., Yan, D., Wang, Y., Dong, B., Wang, J., et al. (2020). Classification of Instream Ecological Water Demand and Crucial Values in a Semi-arid River basin. Sci. Total Environ. 712, 136409. doi:10.1016/j.scitotenv.2019.136409

Liu, H., Jia, Y., Niu, C., Su, H., Wang, J., Du, J., et al. (2020). Development and Validation of a Physically-Based, National-Scale Hydrological Model in China. J. Hydrol. 590, 125431. doi:10.1016/j.jhydrol.2020.125431

Liu, J. F. (2019). Research on Identification and Configuration of Green Infrastructure Nodes in Resource-Based Cities. Beijing: China University of Geosciences.

Liu, J., Yin, H. W., Kong, F. H., and Li, M. H. (2018b). Structure Optimization of Circuit Theory-Based green Infrastructure in Nanjing, China. Acta Ecologica Sinica 38, 4363-4372. doi:10.5846/stxb201801250199

Liu, J., Zhang, Z., and Zhang, M. (2018a). Impacts of forest Structure on Precipitation Interception and Run-Off Generation in a Semiarid Region in Northern China. Hydrological Process. 32, 2362-2376. doi:10.1002/hyp.13156

López-Bravo, C., Caetano, E., and Magaña, V. (2018). Forecasting Summertime Surface Temperature and Precipitation in the Mexico City Metropolitan Area: Sensitivity of the WRF Model to Land Cover Changes. Front. Earth Sci. 6, 6. doi:10.3389/feart.2018.00006

Ministry of Ecology and Environment of the People's Republic of China (2015). Technical Criterion for Ecosystem Status Evaluation (H192-2015). Beijing: Ministry of Ecology and Environment of the People's Republic of China. 
Nunes, A., Oliveira, G., Mexia, T., Valdecantos, A., Zucca, C., and Costantini, E. A. C. (2016). Ecological Restoration across the Mediterranean Basin as Viewed by Practitioners. Sci. Total Environ. 566-567, 722-732. doi:10.1016/j.scitotenv. 2016.05.136

Peng, H., Kyriazopoulos, A. P., Salah, A., Prasse, R., Correia, O., Milliken, S., et al. (2015). Eco-hydrological Simulation of Soil and Water Conservation in the Jinghe River Basin in the Loess Plateau, China. J. Hydro-Environment Res. 9, 452-464. doi:10.1016/j.jher.2014.09.003

Piani, C., Weedon, G. P., Best, M., Gomes, S. M., Viterbo, P., Hagemann, S., et al. (2010). Statistical Bias Correction of Global Simulated Daily Precipitation and Temperature for the Application of Hydrological Models. J. Hydrol. 395, 199-215. doi:10.1016/j.jhydrol.2010.10.024

Sun, W., Song, X., Mu, X., Gao, P., Wang, F., and Zhao, G. (2015). Spatiotemporal Vegetation Cover Variations Associated with Climate Change and Ecological Restoration in the Loess Plateau. Agric. For. Meteorology 209-210, 87-99. doi:10.1016/j.agrformet.2015.05.002

Takata, K., and Hanasaki, N. (2020). The Effects of Afforestation as an Adaptation Option: a Case Study in the Upper Chao Phraya River basin. Environ. Res. Lett. 15, 044020. doi:10.1088/1748-9326/ab7462

Tang, Z., Shi, C., and Bi, K. (2014). Impacts of Land Cover Change and Socioeconomic Development on Ecosystem Service Values. Environ. Eng. Manag. J. 13, 2697-2705. doi:10.30638/eemj.2014.300

Treacy, P., Jagger, P., Song, C., Zhang, Q., and Bilsborrow, R. E. (2018). Impacts of China's Grain for Green Program on Migration and Household Income. Environ. Manage. 62, 489-499. doi:10.1007/s00267-018-1047-0

Vicente-Vicente, J. L., Fuss, S., Song, C., Lee, J., Kim, M., Lee, W.-K., et al. (2019). A Holistic View of Soils in Delivering Ecosystem Services in Forests: A Case Study in South Korea. Forests 10, 487. doi:10.3390/f10060487

Wang, G. Q., Zhang, J. Y., Guan, X. X., Bao, Z. X., Liu, Y. L., He, R. M., et al. (2020). Quantifying Attribution of Runoff Change for Major Rivers in China. Adv. Water Sci. 31, 313-323. doi:10.14042/j.cnki.32.1309.2020.03.001

Wang, H., Tetzlaff, D., and Soulsby, C. (2018). Modelling the Effects of Land Cover and Climate Change on Soil Water Partitioning in a Boreal Headwater Catchment. J. Hydrol. 558, 520-531. doi:10.1016/j.jhydrol.2018.02.002

Wang, W., Hu, P., Wang, J., Zhao, J., Liu, H., and Yang, Z. (2021). Scenario Analysis for the Sustainable Development of Agricultural Water in the Wuyuer River basin Based on the WEP Model with a Reservoir and Diversion Engineering Module. Sci. Total Environ. 758, 143668. doi:10.1016/j.scitotenv.2020.143668

Wang, X., He, K., and Dong, Z. (2019). Effects of Climate Change and Human Activities on Runoff in the Beichuan River Basin in the Northeastern Tibetan Plateau, China. Catena 176, 81-93. doi:10.1016/j.catena.2019.01.001

Warszawski, L., Frieler, K., Huber, V., Piontek, F., Serdeczny, O., and Schewe, J. (2014). The Inter-sectoral Impact Model Intercomparison Project (ISI-MIP): Project Framework. Proc. Natl. Acad. Sci. USA 111, 3228-3232. doi:10.1073/pnas.1312330110

Winkler, R. D., Spittlehouse, D. L., and Golding, D. L. (2005). Measured Differences in Snow Accumulation and Melt Among Clearcut, Juvenile, and Mature Forests in Southern British Columbia. Hydrol. Process. 19, 51-62. doi:10.1002/hyp.5757

Winter, S. (2012). Forest Naturalness Assessment as a Component of Biodiversity Monitoring and Conservation Management. Forestry 85, 293-304. doi:10.1093/ forestry/cps004

Wu, G.-L., Liu, Y., Yang, Z., Cui, Z., Deng, L., Chang, X.-F., et al. (2017). Root Channels to Indicate the Increase in Soil Matrix Water Infiltration Capacity of Arid Reclaimed Mine Soils. J. Hydrol. 546, 133-139. doi:10.1016/j.jhydrol.2016. 12.047

Xu, M., Xu, G., Cheng, Y., Min, Z., Li, P., Zhao, B., et al. (2021a). Soil Moisture Estimation and its Influencing Factors Based on Temporal Stability on a Semiarid Sloped Forestland. Front. Earth Sci. 9, 629826. doi:10.3389/feart. 2021.629826

Xu, Z., Fan, W., Wei, H., Zhang, P., Ren, J., Gao, Z., et al. (2019). Evaluation and Simulation of the Impact of Land Use Change on Ecosystem Services Based on a Carbon Flow Model: A Case Study of the Manas River Basin of Xinjiang, China. Sci. Total Environ. 652, 117-133. doi:10.1016/j.scitotenv.2018.10.206

Xu, Z., Liu, W., Li, Q., Wu, J., Duan, H., Huang, G., et al. (2021b). Responses of Intra-annual Runoff to forest Recovery Patterns in Subtropical China. J. For. Res. 32, 1479-1488. doi:10.1007/s11676-020-01219-2
Yan, D. H., Wang, H., Zhang, J. Y., Wang, Z. L., Xing, Z. Q., and Qin, T. L. (2017). From Changing Status to Improving Capability: Construction of an Ecological Sponge-Smart River Basins. Adv. Water Sci. 28, 302-310. doi:10.14042/j.cnki. 32.1309.2017.02.016

Yan, D. H., Wang, H., Zhou, M., and Qin, T. L. (2020). Scientific Ideas and Development Prospects of Global Water Management Modes. Water Resour. Prot. 36, 1-7. doi:10.3880/j.issn.1004-6933.2020.03.001

Yang, D. W., Lei, H. M., and Cong, Z. T. (2010). Overview of the Research Status in Interaction between Hydrological Processes and Vegetation in Catchment. J. Hydraulic Eng. 41, 1142-1149. doi:10.13243/j.cnki.slxb.2010.10.001

Yang, W., Long, D., and Bai, P. (2019). Impacts of Future Land Cover and Climate Changes on Runoff in the Mostly Afforested River basin in North China. J. Hydrol. 570, 201-219. doi:10.1016/j.jhydrol.2018.12.055

Yang, Y., Weng, B., Yan, D., Niu, Y., Gong, X., and Li, M. (2020). Method for Assigning Hydrological Computational Units in alpine Watersheds. J. Hydrol. Reg. Stud. 32, 100759. doi:10.1016/j.ejrh.2020.100759

Yu, X., Huang, Y., Li, E., Li, X., and Guo, W. (2018). Effects of Rainfall and Vegetation to Soil Water Input and Output Processes in the Mu Us Sandy Land, Northwest China. Catena 161, 96-103. doi:10.1016/j.catena.2017.10.023

Zhang, C., Shen, Y., Liu, F., and Meng, L. (2016b). Changes in Reference Evapotranspiration over an Agricultural Region in the Qinghai-Tibetan Plateau, China. Theor. Appl. Climatol 123, 107-115. doi:10.1007/s00704-014-1335-4

Zhang, J. Y., Wang, G. Q., Jin, J. L., He, R. M., and Liu, C. S. (2020). Evolution and Variation Characteristics of the Recorded Runoff for the Major Rivers in China during 1956-2018. Adv. Water Sci. 31, 153-161. doi:10.14042/j.cnki.32.1309. 2020.02.001

Zhang, X. W., and Chen, T. (2017). "Research on Spatial Optimization Strategies of Existing Urban Areas Based on Green Infrastructure," in Sustainable Development and Rational Planning-Proceedings of 2017 China Urban Planning Annual Conference (08 Urban Ecological Planning), Dongguan, China, November 18, 2017, 9.

Zhang, Y., Peng, C., Li, W., Tian, L., Zhu, Q., Chen, H., et al. (2016a). Multiple Afforestation Programs Accelerate the Greenness in the 'Three North' Region of China from 1982 to 2013. Ecol. Indicators 61, 404-412. doi:10.1016/j.ecolind. 2015.09.041

Zheng, Y., Dong, L., Xia, Q., Liang, C., Wang, L., and Shao, Y. (2020). Effects of Revegetation on Climate in the Mu Us Sandy Land of China. Sci. Total Environ. 739, 139958. doi:10.1016/j.scitotenv.2020.139958

Zhou, G. S., and Wang, Y. H. (1999). The Feedback of Land Use/cover Change on Climate. J. Nat. Resour. 4, 318-322.

Zhou, R. P. (2019). Assessing the Soil Erosion Control Service in the Typical Area of Loess Plateau. Remote Sensing Land Resour. 31, 131-139. doi:10.6046/gtzyyg. 2019.02.19

Zhou, Z., Jia, Y., Qiu, Y., Liu, J., Wang, H., Xu, C.-Y., et al. (2018). Simulation of Dualistic Hydrological Processes Affected by Intensive Human Activities Based on Distributed Hydrological Model. J. Water Resour. Plann. Manage. 144, 04018077. doi:10.1061/(ASCE)WR.1943-5452.0000990

Conflict of Interest: The authors declare that the research was conducted in the absence of any commercial or financial relationships that could be construed as a potential conflict of interest.

Publisher's Note: All claims expressed in this article are solely those of the authors and do not necessarily represent those of their affiliated organizations, or those of the publisher, the editors, and the reviewers. Any product that may be evaluated in this article, or claim that may be made by its manufacturer, is not guaranteed nor endorsed by the publisher.

Copyright $\odot 2022$ Qin, He, Liu, Nie, Dong and Lv. This is an open-access article distributed under the terms of the Creative Commons Attribution License (CC BY). The use, distribution or reproduction in other forums is permitted, provided the original author(s) and the copyright owner(s) are credited and that the original publication in this journal is cited, in accordance with accepted academic practice. No use, distribution or reproduction is permitted which does not comply with these terms. 